\title{
Pesquisando com jovens na escola: desafios da pesquisa-intervenção em dois contextos escolares
}

\author{
Luciana Lobo Miranda \\ Universidade Federal do Ceará - Fortaleza - CE - Brasil \\ Eveline Nogueira Pinheiro de Oliveira \\ Universidade Federal do Ceará - Fortaleza - CE - Brasil \\ Júlia Evangelista Mota Shioga \\ Escola de Saúde Pública do Ceará - Fortaleza - CE - Brasil \\ Denise Costa Rodrigues \\ Universidade Federal do Ceará - Fortaleza - CE - Brasil
}

\section{Resumo}

O artigo tece reflexões sobre a Psicologia Educacional a partir da construção de um processo de pesquisa em duas escolas públicas da periferia de Fortaleza-CE. A pesquisa adotou a perspectiva teórico-metodológica da pesquisa-intervenção com base na Análise Institucional francesa e propôs investigar o entrelaçamento entre escola pública, mídia e juventude. O objetivo do artigo foi discutir as relações intraescolares evidenciadas na dinâmica da pesquisa, com ênfase no aspecto metodológico, no processo de pesquisar com as escolas. Os procedimentos utilizados foram restituições, observações participantes, conversas com gestores e oficina de vídeo. Acontecimentos analisadores evidenciaram relações intraescolares atravessadas pela indisciplina e pelos usos não autorizados da mídia em sala de aula, assim como repercussões do mundo laboral no cotidiano escolar: competição, profissionalização e falta de tempo. A análise do processo de pesquisar COM jovens e COM escolas trouxe diversos questionamentos e a compreensão de que a invenção de novas práticas e a (re)invenção da pesquisa são fundamentais. Palavras-chave: Escola; pesquisa-intervenção; juventude.

\section{Searching with young people in school: the challenges of intervention research in two school settings}

\begin{abstract}
The article is about some reflections on the Educational Psychology from the construction of a research process in two public schools on the outskirt of Fortaleza. The research adopted the theoretical and methodological perspective of intervention research based on French Institutional Analysis and proposed to investigate the connections between public school, media and youth. The purpose of this article was to discuss the relations among the people inside the school highlighted by the dynamics of the research, with emphasis on methodological aspect in the process of research with schools. The procedures used were the refunds, participant observations, conversations with managers and video workshop. The events analyzers showed the relations among the people inside the school were traversed by the indiscipline and the unauthorized uses of media in the classroom, as well as repercussions of working life in school life; competition, professionalism and lack of time. The analysis of the research process WITH young and WITH schools brought many questions and the understanding that the invention of new practices and the (re) invention of research are fundamental.
\end{abstract}

Keywords: School; research intervention; youth.

\section{Pesquisando con jóvenes en la escuela:}

\section{desafíos de la pesquisa-intervención en dos contextos escolares}

\section{Resumen}

El artículo hace reflexiones sobre la Psicología Educacional a partir de la construcción de un proceso de investigación en dos escuelas públicas de la periferia de Fortaleza-CE. La investigación adoptó la perspectiva teórico-metodológica de la pesquisa-intervención con base en el Análisis Institucional francesa y propuso investigar el entrelazamiento entre escuela pública, media y juventud. El objetivo del artículo fue discutir las relaciones infra-escolares evidenciadas en la dinámica de la investigación, con énfasis en el aspecto metodológico, en el proceso de pesquisar con las escuelas. Los procedimientos utilizados fueron restituciones, observaciones participantes, charlas con gestores y taller de vídeo. Hechos analizadores evidenciaron relaciones infra-escolares atravesadas por la indisciplina y por los usos no autorizados de la media en sala de clase, así como repercusiones del mundo laboral en el cotidiano escolar: competición, profesionalización y falta de tiempo. El análisis del proceso de pesquisar CON jóvenes y CON escuelas trajo diversos cuestionamientos y la comprensión de que la invención de nuevas prácticas y la (re) invención de la pesquisa son fundamentales.

Palabras clave: Escuela; pesquisa-intervención; juventud. 


\section{Introdução}

O presente trabalho discute o processo de uma pesquisa-intervenção com duas escolas públicas da cidade de Fortaleza - CE. Pretendemos analisar as condições da pesquisa, cuja ênfase está no pesquisar não SOBRE os jovens estudantes de ensino médio, ou SOBRE as escolas envolvidas, como se a pesquisa pudesse revelar uma verdade escondida. O que é discutido aqui é a possibilidade de pesquisar COM os jovens e COM as escolas. Na pesquisa-intervenção em questão o que produz e constrói a pesquisa é o entrelaçamento da rede heterogênea pesquisadores-jovens-escola, compondo uma cena enunciativa, isto é, práticas discursivas e não discursivas que ajudam a tecer uma certa composição da pesquisa, na qual cabe sempre analisar as próprias condições da pesquisa em sua dimensão processual (Aguiar \& Rocha, 2007). Assim, discutir a metodologia da pesquisa é discutir certo modo de estar COM o outro (Moraes, 2014).

Com base na hipótese da presença e incidência da mídia nos modos de subjetivação da juventude contemporânea, sobretudo em contexto urbano e escolar, foi realizada uma pesquisa intitulada Juventudes e Mídia: Um estudo sobre o consumo, apropriação e produção de mídia por jovens estudantes de Escola Pública de Fortaleza ${ }^{1}$, a qual se propôs investigar o entrelaçamento escola pública, mídia e juventude em dois contextos escolares. O termo mídia normalmente refere-se ao conjunto dos meios de comunicação social analógicos ou digitais, de que são exemplos a imprensa, a televisão e a internet (Miranda, 2014a). Se em outros trabalhos foram analisados dados decorrentes da relação juventude-mídia (Miranda, Khouri, Rodrigues, Amaral, \& Sousa, 2013; Miranda, 2014a; Miranda, Souza FiIho, Queiroz, Viana, \& Coelho, no prelo), a ênfase aqui será no aspecto metodológico, no processo de pesquisar e na construção de dois territórios de pesquisa em duas escolas públicas, com base na pesquisa-intervenção.

O território deve ser compreendido como o conjunto formado a partir do espaço e da circulação de poderes permanentemente em disputa neste espaço, de modo que o território é constituído não apenas em sua dimensão física, mas por relações interespaciais de poder (Foucault, 1979).

Utilizando a perspectiva teórico-metodológica da pesquisa-intervenção, neste artigo tecemos reflexões no âmbito da Psicologia Educacional sobre o processo de pesquisar em duas escolas distintas. Problematizamos como a construção da pesquisa diz respeito ao território que ela habita. Nesse sentido, questionamos como se deu a entrada da pesquisa nas escolas e como cada escola de certa forma também aderiu à pesquisa, analisando aproximações e distanciamentos observados em cada processo. Consideramos, pois, o modo como se construiu a relação que estabelecemos com as escolas pesquisadas e como as características específicas destas influenciaram no próprio processo de pesquisa. Moraes (2014) afirma que a atitude

1 Pesquisa financiada pelo CNPq e aprovada pelo Comitê de Ética em Pesquisa (CEP) com o protocolo 200.729. de pesquisar COM é sempre mais instigada pelas variações do que propriamente pelos invariantes. Assim objetivamos discutir o pesquisar COM duas escolas públicas da periferia de Fortaleza-CE, observando dois pontos que se destacaram na dinâmica da pesquisa: as relações intraescolares e os atravessamentos do mundo laboral no cotidiano escolar. Imprevisibilidades surgidas numa pesquisa que se propunha analisar as relações dos jovens com a mídia.

As duas escolas públicas da periferia de Fortaleza em que as pesquisas foram realizadas mostraram características próprias que as distinguiram. Apesar de se tratar da mesma proposta de pesquisa-intervenção para ambos os territórios constatamos que os processos de pesquisar com as escolas se configuraram, muitas vezes, de modos diferentes.

Nesse sentido, neste trabalho nos interrogamos: Como se constituem os cotidianos das escolas em relação à pesquisa? No espaço de ação da pesquisa, como se dão os modos de convivência entre núcleos gestores, professores e alunos? Como a pesquisa realizada no âmbito escolar coloca em evidência relações já presentes em seu cotidiano?

Na pesquisa-intervenção em questão o que produz e constrói a investigação é o entrelaçamento da rede heterogênea pesquisadores-jovens-instituição escolar, compondo uma cena enunciativa na qual cabe sempre analisar as condições da pesquisa em sua dimensão processual.

Para realizarmos a escolha das escolas elencamos os seguintes critérios: participação na pesquisa quantitativa anteriormente realizada²; participação na restituição da pesquisa quantitativa em fórum realizado na Universidade Federal do Ceará- UFC; apresentação de alto índice de produção de mídia, segundo comparação dos dados construídos na pesquisa quantitativa; interesse em participar do projeto. Foi nessa conjuntura que iniciamos a pesquisa em ambas as escolas.

A primeira escola participante caracteriza-se por ser uma Escola Estadual de Educação Profissional (EEEP), proveniente da rede Estadual de Ensino Médio. Inaugurada em 1979, tornou-se em 2010 integrante da rede de ensino profissionalizante do Ceará, por meio do programa federal Brasil Profissionalizado. Em 2013 a instituição atendeu cerca de 160 estudantes em período integral, tanto com ensino propedêutico quanto profissionalizante (com cursos de Administração, Redes Informacionais, Secretariado e Contabilidade). As instalações, apesar de adequadas, eram provisórias, pois a escola aguardava a finalização do prédio definitivo nas imediações, com estrutura específica para os referidos cursos.

A segunda instituição, uma Escola de Ensino Fundamental e Médio (EEFM), fundada em 1968, em 2014 teve

2 A pesquisa Adolescência e Juventude Brasileira: Situações de Risco e Redes de Proteção na cidade de Fortaleza foi realizada no período de 2009 a 2011 e teve como objetivo traçar o perfil dos jovens estudantes de escola pública de Fortaleza. Contou com a participação de 43 escolas, nas quais foram aplicados questionários em 1.140 estudantes entre 14 e 24 anos de idade, com variados temas, tais como: educação, sexualidade, lazer, violência e drogas, dentre outros (COLAÇO \& CORDEIRO, 2013). 
1376 estudantes matriculados, sendo 696 cursando o Ensino Médio, foco da pesquisa. O funcionamento da Escola ocorria nos três turnos: pela manhã, funcionava o Ensino Fundamental; no período da tarde, ocorriam as atividades voltadas para o Ensino Médio e à noite a Educação de Jovens e Adultos (EJA), além de possuir turmas do Ensino Médio regular.

Portanto, pesquisamos com duas escolas distintas: uma profissionalizante, de tempo integral e exclusiva de Ensino Médio; e outra, Regular com Ensino Fundamental e Médio, de meio período, ambas situadas na periferia de Fortaleza. Cada escola, apesar de um território em comum (cotidiano marcado por aulas, intervalos, currículos,, relações interpessoais entre alunos, professores, funcionários e núcleo gestor, precarização laboral etc), tinha sua própria dinâmica e suas especificidades. Por isso buscamos fugir do olhar comum que busca invariantes para ir ao encontro da singularidade de cada dinâmica escolar, que significa produzir um encontro com as escolas envolvidas, onde se destaca a micropolítica do cotidiano para a construção de analisadores (Rocha e Aguiar, 2010). Embora tivéssemos um objeto comum em ambas as escolas, a saber, a relação juventude e mídia dentro e fora de espaços escolares, a própria postura teórico-metodológica da pesquisa intervenção (discutida a seguir) nos indicava a importância de trabalhar considerando a singularidade de cada território escolar.

\section{Método}

\section{Pesquisar com as escolas: $O$ que isso (re)significa?}

Consoante a Aguiar e Rocha (2007), quando um grupo de pesquisadores se reúne e se propõe a pesquisar-intervir em determinado território, o objetivo não é coletar dados de pesquisa. Ao contrário, o objetivo é que a construção de dados com o outro provoque transformação não só no cotidiano institucional, mas também na própria dinâmica da pesquisa. Não se trata de "ir a campo" para comprovar certezas prévias, pois embora se tenham algumas desconfianças com relação ao objeto da pesquisa, é preciso colocá-las no território da imprevisibilidade, e, portanto fazê-las também passíveis de transformação (Moraes, 2014).

As pesquisas participativas são estratégias que têm como proposta a interpelação de grupos sociais na busca de alternativas para as situações vividas, envolvendo um processo de compreensão e transformação da realidade (Aguiar e Rocha, 2007). Para desenvolver uma metodologia participante, uma mudança na postura do pesquisador e dos sujeitos é necessária, uma vez que todos são considerados protagonistas no processo da pesquisa. Nesse sentido, a pesquisa-intervenção, compreendendo que o sujeito se produz em meio às práticas sociohistóricas, implica em uma tendência das pesquisas participativas que intenta investigar a vida de coletividades na sua diversidade (Aguiar e Rocha, 2007; Rocha, 1996, 2001).
Entendendo que a neutralidade não é possível, adotamos a pesquisa-intervenção com base na Análise Institucional de tradição francesa (Lourau e Lapassade) e da filosofia da diferença (Deleuze, Guattari e Foucault) que contribuem teoricamente para pensar o ato de pesquisa como ato político. Ao colocarem em xeque a neutralidade, não pressupõem a conscientização do outro, isto é, não se colocam centradas na consciência, em que o conhecimento (a priori) levaria à autonomia, mas problematizam as próprias relações de poder presentes no cotidiano da pesquisa, inserindo-o na trama entre saber e poder (Aguiar \& Rocha, 2007; Paulon, 2005). Buscamos assim coadunar e centralizar a intervenção do pesquisador no que seria seu objetivo, enquanto consideramos o que surge ao longo do processo, o imprevisível (Castro, 2008). O pesquisador se propõe a ser analisador, ciente de sua própria implicação, em aspectos como a formulação do objeto de pesquisa, sua encomenda social, suas implicações epistemológicas e de exposição (Paulon, 2005). Segundo Aguiar e Rocha (2007, p. 21):

Nesta perspectiva, pesquisar é, antes de mais nada, uma atitude que interroga os homens e os fatos em seus processos de constituição, trazendo para o campo de análise as histórias, o caráter transitório e parcial, os recortes que a investigação imprime nas práticas e a forma como produz seus próprios objetos-efeitos.

O processo de pesquisa implica assim na produção de analisadores, (Aguiar e Rocha, 2007). O conceito de analisador diz respeito ao descentramento da figura do analista para o processo do encontro, do entre que se forma no próprio processo de pesquisar. Os acontecimentos analisadores funcionam como "catalisadores de sentido", pois desnaturalizam as condições instaladas e desestabilizam práticas cotidianas que parecem estáticas. A análise não é exclusiva do pesquisador, mas o próprio acontecimento pode se tornar analisador, onde o pesquisador certamente também faz parte, sobretudo no momento da escrita. $\mathrm{O}$ analisador refere-se a todo dispositivo que permita, a partir de uma análise de decomposição do que aparecia até então como uma totalidade homogênea (uma verdade instituída), desvelar o caráter fragmentário, parcial e polifônico de toda realidade.

Outro conceito fundamental na Análise Institucional é a análise de implicação (Loureau 1993; Paulon 2005;). Como há reconhecimento de que a neutralidade é impossível, o pesquisador não se retira dos efeitos analisadores de sua atuação. Investigam-se seriamente quais os efeitos do lugar ocupado, que é designado a ocupar ou que é buscado pelo pesquisador, e as consequências de suas posições são analisadas (Aguiar \& Rocha, 2007; Lourau, 1993; Paulon, 2005). Assim, o presente trabalho é fundamentalmente permeado pela análise de implicação, como lente utilizada para analisar as cenas analisadoras da pesquisa em questão. Outro recurso ainda é a restituição. Esta se diferencia da devolutiva por não se tratar de apresentar os resultados para os sujeitos envolvidos em um momento posterior à pesquisa. Ao contrário, a restituição caracteriza-se como constitutiva da pesqui- 
sa, onde algumas análises são debatidas, para que juntos, pesquisadores e sujeitos da pesquisa, possam atribuir novos sentidos aos acontecimentos (Aguiar \& Rocha, 2007; Loureau 1993; Paulon, 2005; Santos \& Barone, 2006).

Após a negociação com os núcleos gestores, a primeira atividade desta pesquisa-intervenção foi a momento de restituição dos dados quantitativos em cada escola. Com a presença de mais de 100 alunos em cada escola, analisamos coletivamente com professores, estudantes e gestores os resultados obtidos e os desdobramentos desses dados no momento presente ${ }^{3}$.

Em cada campo, após a realização da restituição dos dados quantitativos, houve um período de inserção dos pesquisadores no cotidiano escolar de cerca de três meses em cada escola. O intuito foi conhecer a rotina e o ambiente, começando a habitar os territórios da pesquisa. Realizamos visitas semanais de aproximadamente quatro horas cada durante cerca de doze semanas, e participações em reuniões, além de conversas informais com professores, alunos e núcleo gestor. Ora observávamos a sala de professores, ora o pátio, ora as aulas no Laboratório de Informática (LEI). Após esse período, realizamos o convite aos estudantes de primeiro e segundo ano de Ensino Médio para participação numa oficina de vídeo, dispositivo de intervenção criado pela pesquisa. O critério para a participação na oficina de vídeo foi o interesse e a entrega do termo de consentimento livre e esclarecido (TCLE) assinado seja pelos responsáveis, no caso de menor de idade, seja pelo próprio estudante, no caso de maior ou igual a 18 anos.

Realizada em cada escola, a oficina teve como objetivo a produção de vídeos pelos estudantes com base na discussão da incidência da mídia nos seus modos de subjetivação. A oficina contou com carga horária de 20 horas (cinco encontros com quatro horas cada), nas quais abordamos temas relacionados à linguagem audiovisual, fotografia, sonorização e reflexões acerca da relação da juventude e mídia. A tematização sobre a relação dos jovens com a mídia foi instigada pela exibição de vídeos em diferentes linguagens, envolvendo direta ou indiretamente o tema da pesquisa, de modo que o vídeo foi utilizado tanto como objeto de discussão (análise de publicidade, programa jornalísticos, ficção com temas relacionados à mídia), quanto para expressão de si, através da apropriação da linguagem midiática na produção de vídeos em grupo, com o tema juventude e mídia (Miranda, 2014b).

Todos os encontros foram gravados em vídeo, seja pelos pesquisadores ou pelos próprios jovens estudantes,

\footnotetext{
3 Ao discutirmos com os estudantes, professores e gestores os dados levantados através dos questionários da pesquisa quantitativa, observamos que, em menos de dois anos, a relação dos jovens com a mídia havia sofrido modificações consideráveis. $\mathrm{Na}$ pesquisa quantitativa, as três atividades mais pontuadas foram assistir TV $(86,7 \%)$, escutar ou tocar música $(76,1 \%)$ e navegar na internet $(63,6 \%)$. (Miranda, Khouri, Rodrigues, Amaral, \& Sousa, 2013). Contudo, no momento da restituição dos respectivos dados, constatou-se que a internet predominava em detrimento da TV, provocando a primeira mudança na pesquisa, tanto do ponto de vista teórico-conceitual que incorporasse a internet e os modos de subjetivação juvenis na análise, quanto metodológicos para criar estratégias de discussão desta relação com as escolas envolvidas.
}

e posteriormente foram transcritos. A fim de facilitar nossa comunicação com os participantes da pesquisa quando não estávamos nas escolas, criou-se também um grupo de discussão em uma rede social digital extremamente popular entre os estudantes, o facebook ${ }^{4}$, para postagens relacionadas aos aspectos práticos da oficina de vídeo, (dia e horário dos encontros por exemplo). Nesta rede, tanto o grupo de pesquisadores quanto os jovens postavam fotos, ou teciam comentários sobre a oficina de vídeo, constituindo um território, mesmo que virtual, da pesquisa.

Na EEEP, formou-se um grupo com 21 estudantes, de ambos os sexos, que produziram quatro vídeos, a saber: A) "Verdade": gênero ficcional sobre a interação da mídia com seu usuário, apresentando um estudante que não se envolve com computador e redes sociais, preferindo os livros, e um jovem que parece viver apenas no mundo virtual. Há ao fim uma mensagem de equilíbrio; B) "Só mais um besteirol": vlog (uma variante de weblog em forma de vídeo) em que os estudantes dizem de seus usos cotidianos da internet respondendo a questões fictícias, elaboradas por eles mesmos; C) "Viaje nas ideia!": Ficção e com recurso de stopmotion (técnica de animação) comparando, de acordo com os interesses dos jovens, as mídias utilizadas pelos jovens nas décadas de 1980, 1990 e nos anos 2000, apresentando uma espécie de progresso em que a contemporaneidade seria a Ficção e com recurso de stopmotion (técnica de animação) comparando, de acordo com os interesses dos jovens, as mídias utilizadas pelos jovens nas décadas de 1980, 1990 e nos anos 2000, apresentando uma espécie de progresso em que a contemporaneidade seria o melhor estágio; D) "Vamos brincar de quê?": Ficção sem diálogo apenas música, que narra uma espécie de linha do tempo composta por dois períodos - no primeiro, brincadeiras de rua constituem o universo juvenil, enquanto no segundo, adolescentes se voltam para jogos de computador e celulares.

$\mathrm{Na}$ EEFM, 10 participantes de ambos os sexos e alguns membros da rádio escola produziram cinco pequenas narrativas, todas envolvendo o uso do celular, juntas em um só vídeo intitulado "O Mundo com Celular". O celular smartphone (celular com tecnologias avançadas, o que inclui programas executados um sistema operacional, equivalente aos computadores) é retratado em destaque, por possibilitar o acesso à internet a qualquer momento, demonstrando o quanto a comunicação virtual pode modificar as relações face a face. A publicação de acontecimentos cotidianos na rede também foi algo mencionado pelos alunos, bem como a vulnerabilidade deles diante dos assaltos a celulares. $\mathrm{Na}$ história "O Facebook vicia mais", os alunos tecem uma comparação entre vício na internet e o vício em drogas ilícitas, afirmando que o primeiro vicia mais do que o segundo. A oficina também contou com a participação da professora do Laboratório de informática (LEI), locus da oficina. Apesar de ter sido planejada para os estudantes, a proximidade entre a

\footnotetext{
4 Facebook é uma rede social criada nos EUA em 2004, que “... dá às pessoas o poder de compartilhar informações e fazer do mundo um lugar mais aberto e conectado." (https://www.facebook.com/ FacebookBrasil/info?ref=page_internal, recuperado: 04/11/2014).
} 
professora e os estudantes fez com que ela se interessasse em participar das atividades.

Em ambas as escolas, a pesquisa contou com mais um momento de restituição, dessa vez dos dados qualitativos, no qual os estudantes participantes das oficinas puderam apresentar seus respectivos vídeos, fruto da pesquisa, para professores, gestores e demais alunos, bem como discutir sobre a oficina, a escolha da temática do vídeo e seu processo de construção. Assim como na primeira restituição, o momento foi relevante para a observação das relações estabelecidas na teia estudantes-gestores-professores.

A pesquisa-intervenção construída em cada território escolar foi negociada com alunos, professores e núcleos gestores. Na análise das aproximações e distanciamentos desses processos, os acontecimentos analisadores nos auxiliam na problematização de cada processo de forma singular. Em uma pesquisa-intervenção que se propõe discutir a relação juventude e mídia e que tem como território de produção de dados a escola, precisa se interrogar sobre como este cenário ajuda a constituir o próprio processo da pesquisa. Isto é, trata-se de se interrogar de como a pesquisa entra na escola e como a escola entra na pesquisa.

$\mathrm{Na}$ intensidade das trocas estabelecidas ao longo de quase um ano de pesquisa em cada escola, discutiremos alguns acontecimentos analisadores que dizem respeito ao pesquisar com as escolas; são eles: as relações intraescolares e a interpelação do mundo profissional no cotidiano escolar.

\section{Resultados}

\section{As relações intraescolares e o cotidiano da pesquisa}

A oficina de vídeo, dispositivo criado pela pesquisa, foi um espaço novo, mas marcado por vetores já existentes em ambas as escolas. Este dispositivo colocou em evidência singularidades características de cada cotidiano escolar, provocando uma ressignificação das relações intraescolares na pesquisa.

Trazemos uma cena analisadora. Durante a gravação de um vídeo na Escola Profissionalizante (EEEP), que ocorria excepcionalmente na sala de multimeios, por ser a única sala disponível na ocasião, a professora responsável por esta sala teve o primeiro contato com o cotidiano da pesquisa. Antes a relação com a oficina de vídeo, que sempre ocorria em outra sala, restringia-se ao agendamento e ao empréstimo de algum material. Na gravação, os alunos debatiam qual seria o tema de perguntas para o Vlog, vídeo que estavam construindo. A conversa fluía entre risos e piadas, quando surgiu a possibilidade de haver alguma pergunta sobre homossexualidade. A professora que até então assistia à gravação, incomodou-se e interveio para impedir que os alunos tratassem do referido tema.
João [dirigindo-se ao colega]" : Só pra te agradar, vamos falar do homossexualismo, que está sendo uma polêmica (Risos). $\mathrm{Ei}$, a gente tinha falado de trazer polêmica de alguma coisa".

Ricardo: "Eu não vou falar sobre homossexualismo".

George: "Os beijos na quadra" (Risos).

A professora interfere na conversa.

Ana (professora): "Mas não vamos por esse lado, que vocês não são adultos pra discutir isso aí".

Larissa: "É porque é nossa opinião".

Ana (professora): "Porque é assim... Vocês não têm maturidade ainda em assumir e discutir esse assunto".

Luciana (pesquisadora): "Pra gente que está organizando a pesquisa, é importante que eles tenham o processo deles; pra gente é importante isso".

Para os jovens estava claro que era a opinião deles que contava para a pesquisa. Este acontecimento-analisador parece evidenciar, no entanto, uma recorrência no ambiente escolar: um adulto informa para os estudantes que eles não podem expressar determinada opinião porque não seriam plenamente desenvolvidos (Castro, 2011).

A análise de implicação, ao analisar as condições da própria pesquisa, coloca em debate a relação de poder que se constitui entre a pesquisa e o campo. Nos encontros entre os pesquisadores, ao longo de nossa inserção, questionávamos o nosso lugar de verdade ora atribuídos por eles, ora por nós mesmos. A cena descrita acima tornou-se um analisador tanto das relações de poder existentes na escola, quanto da nossa própria implicação com a pesquisa. Se, de um lado, procurávamos nos afastar do lugar de verdade e tentávamos configurar na oficina um campo de troca, onde as falas e experiências dos jovens não deveriam ser classificadas por nós como corretas ou equivocadas, por outro, a nossa posição naquele momento também demarcava um lugar hierarquicamente superior: éramos nós que deveríamos garantir o espaço de fala dos alunos. Apesar de estarmos utilizando o espaço físico da escola, é como se disséssemos "este nosso espaço não reconhece a fala da professora como legítima".

Já na EEFM fomos surpreendidos com um acontecimento que desconstruiu a ideia da existência das mesmas relações cristalizadas e verticalizadas entre professor-aluno no ambiente escolar. Ao propormos a oficina de vídeo aos alunos, a professora responsável pelo laboratório de informática (LEI) se dispôs a participar também. De início, achamos que a presença dela poderia interferir no processo da pesquisa e na expressão dos estudantes. Contudo, no decorrer da oficina se confirmou uma relação de confiança entre a professora e

5 Adotamos nomes fictícios para os alunos participantes da pesquisa. Fala transcrita sem modificação das normas gramaticais. 
os jovens. Em um dia da oficina, por exemplo, ao discutirmos os usos não autorizados do celular em sala de aula, os alunos afirmaram utilizar seus smartphones no intuito de jogar, acessar o Facebook e até mesmo "colar" nas provas. Desinibido, um estudante chegou a encenar para a equipe de pesquisa, colegas e professora, a forma como faziam para manipular o aparelho durante provas e exames. Esta situação evidenciou a relação de confiança e o vínculo que a professora do LEI estabelecia com o corpo discente em sua prática pedagógica, que se tornaram ainda mais fortalecidos no cotidiano da oficina de vídeo, dispositivo criado pela pesquisa. A professora foi ao mesmo tempo facilitadora e aprendiz no processo, se distanciando da posição de sujeito que ocupa um lugar de saber-poder na hierarquia da instituição escolar.

Por outro lado, ao iniciarmos a oficina de vídeo na EEEP, primeiro território contatado pelo grupo de pesquisa, solicitamos no início que os alunos escutassem o conteúdo acerca da linguagem para que depois fizessem as perguntas, a fim de não "atrapalhar o conteúdo", dinâmica muito próxima ao cotidiano de sala de aula, marcada pela disciplinarização dos corpos (Foucault, 2007) que tanto questionávamos. Relações de saber-poder que marcam não apenas as relações intraescolares, mas que se constituem na própria pesquisa. Esta atitude foi posteriormente questionada em nossa reunião de pesquisa e redimensionada para uma atitude mais dialógica na oficina de vídeo.

Outro exemplo analisador do entrelaçamento das relações intraescolares e a pesquisa foi a questão do acesso à internet nas escolas. Ainda que os estudantes da EEEP e EEFM a acessassem, percebíamos certa dificuldade para se manterem conectados. Na EEFM, por não haver rede wi-fi, a alternativa encontrada era o uso da internet móvel não gratuita, do tipo 3G. Mesmo na EEEP, que dispunha de rede wi-fi, a senha não era liberada para os estudantes, e um tipo de contra controle foi observado. Diante do não fornecimento da senha pelos gestores, os alunos não viam nenhum problema em tentar obtê-la por meio de aplicativos e programas. Esse aspecto foi observado durante a gravação do vídeo "Viaje nas ideia!", no qual os participantes precisavam do auxílio da internet e, mediante a restrição da senha aos estudantes, um dos alunos propôs ao grupo baixar um aplicativo do celular que poderia hackear a senha de qualquer rede. Salienta-se que se tratava de um grupo composto por estudantes do curso profissionalizante de informática.

Alguns estudantes ratificavam a atitude da gestão e afirmavam que a senha não deveria mesmo ser liberada para todos, pois isto tanto deixaria a navegação lenta quanto desviaria a atenção das aulas. Tão tranquilamente como é aceito que a rede wi-fi não seja liberada, é aceito pelos estudantes que seja usada "clandestinamente". Não se considerava a possibilidade de um acordo coletivo para a utilização racional da rede. A lógica instituída era sempre: proibição e indisciplina, controle e contra controle. Os tensionamentos acerca do limite de acesso à internet e as resistências insurgidas na possibilidade de hackear a senha se evidenciavam na própria cena enunciativa da pesquisa. Aqui se apresentam limites da intervenção da pesquisa, pois embora a postura dos pesquisadores fosse de que os estudantes dispusessem de recursos para criticar, decidir e criar sua relação com a mídia, em alguns momentos isso era barrado pela própria dinâmica escolar.

Também na EEEP observamos um mecanismo de controle muito peculiar utilizado pelos gestores. Segundo relato dos estudantes, o coordenador utilizava a rede social digital Facebook para monitorar os estudantes que estavam online no horário de aula. Assim, os alunos comentaram que era comum estarem acessando a rede social durante a aula e receber uma mensagem via Facebook do coordenador chamando sua atenção. Um dos alunos chegou a afirmar que esta seria obrigação do gestor, adaptada agora às novas tecnologias. É evidente, nesse caso, que o controle do corpo discente em sala de aula está tomando novas formas e sendo aceito com naturalidade, pois já é esperado que haja controle, e por vezes ele parece preferível à discussão sobre os conflitos. A esse respeito, Foucault (1979) salienta que na contemporaneidade há a substituição do poder rígido por um poder mais tênue, suave e elegante sobre o corpo, ao mesmo tempo em que se torna mais difícil mapeá-lo e burlá-lo e, por isso, tal maneira de exercer o poder é bem mais eficaz no cumprimento de seus objetivos. Estas novas formas de controle se inserem pouco a pouco no território escolar (Sibilia, 2012).

A questão da indisciplina dos estudantes também atravessou o território da pesquisa. Em conversas informais percebemos por vezes o descontentamento dos gestores e de alguns professores em virtude do comportamento dos estudantes, além de certa expectativa de uma mudança de comportamento provocada pela pesquisa nos estudantes participantes. Certa vez, o coordenador da EEFM, ao falar do problema que tinha com os alunos devido ao uso crescente do celular em sala de aula, afirmou que por ele não haveria celular na escola e que seu sonho era ter um fiscal para cada turma, a fim de vigiar os alunos. A escola, como instituição formada por relações de poder em que a lógica disciplinar ainda é bastante presente, é um espaço marcado por norma, hierarquia e vigilância (Foucault, 2007; Sibilia, 2012).

A indisciplina dos alunos associada a outros fatores do cotidiano docente acaba por refletir na postura de alguns professores, que adotam comportamentos ríspidos, contribuindo para o aumento das tensões com os alunos. $\mathrm{Na}$ EEFM, os estudantes salientaram a fala de alguns professores nesse sentido. Segundo os alunos alguns professores dizem que na "sua" sala de aula o professor é que é a autoridade.

Para Boarini (2013), o educador, tal como o aluno, parece não ter entendimento claro a respeito do significado e da razão de ser da disciplina, praticamente traduzida através do silêncio, da ordem e de outros comportamentos afins. A disciplina não pode ser entendida como comportamento padronizado, rígido. Segundo a autora, é necessário abdicar da ideia do aluno naturalmente indisciplinado para que se possa compreender os vetores que corroboram na manutenção desse fenômeno escolar. Deve-se refletir também 
que a indisciplina, formas de resistência ao instituído, pode estar revelando os conflitos velados da instituição escolar e mostrando a necessidade da adequação dessa instituição ao seu tempo histórico, marcado cada vez mais pela mídia e por novos modos de subjetivação.

Os acontecimentos analisadores aqui problematizados dizem respeito tanto às relações de saber-poder existentes no cotidiano escolar, mas também como estas acabam por atravessar e se produzir no próprio cotidiano da pesquisa, no entre provocado pelo encontro com as escolas.

\section{Atravessamentos do mundo laboral no cotidiano escolar dos jovens}

Outro analisador e uma das especificidades que diferenciam bastante os dois territórios de pesquisa é a modalidade de ensino. Ou seja, o fato de uma escola se tratar de uma EEEP - Escola Estadual de Ensino Profissionalizante e outra de uma EEFM - de Ensino Regular - evidencia muitas questões em relação à dinâmica de cada escola e ao comportamento e relações dos estudantes. Isso porque a ideologia contida na formação das Escolas Profissionalizantes tende a se alinhar com os preceitos de uma série de transformações ocorridas no século $X X$ na esfera da sociedade capitalista e no mundo do trabalho, já que elas têm por objetivo capacitar jovens e adultos para o exercício de atividades produtivas.

Segundo Lukács (conforme citado por Lima e Jimenez, 2011) a educação estabelece com o trabalho uma relação de dependência ontológica e autonomia relativa. Logo, a esfera educacional e o mundo laboral estão interligados, de modo que a educação é colocada como solução para determinados problemas que ultrapassam seus limites de alcance, como por exemplo o desemprego. Nesse sentido, segundo Carvalho e Martins (2013) é o discurso da empregabilidade que sustenta uma reformulação da educação dos estudantes pautada na lógica das competências. Assim, os jovens, que cada vez mais pressionados para serem os melhores, acabam atingidos por um fenômeno comum ao mundo do trabalho sob o discurso do "empowerment" (Nardi, 2006). Joga-se nas mãos desses jovens o poder e a responsabilidade sobre suas vidas e seu futuro.

De acordo com Coelho e Aquino (2009, p. 277), "a literatura tanto do campo psicológico como do sociológico traz a inserção laboral como um evento fundamental dentre aqueles que estão envolvidos nessa transição para a vida adulta". Nessa perspectiva, a lógica da Educação Profissionalizante é invadida ou entra na lógica do mundo "business", pois apela para uma melhor e cada vez mais rápida capacitação dos jovens e inserção destes no mercado de trabalho. Se, em princípio, na sociedade industrial essa noção estava vinculada à compreensão de pleno emprego - melhor opção ao melhor qualificado - hoje ela implica a possibilidade de estar incluído ou excluído do mercado. Então, aqueles mais preparados terão acesso aos postos de trabalho que surgem, ou seja, estarão prontos para aproveitar e adaptar-se às possibilidades que emergirem (Coelho \& Aquino, 2009).
Surgem então a competição e a concorrência como lógica natural, tanto nas empresas, quanto nas escolas.

A lógica da competição e da concorrência acabou por se configurar como um analisador no nosso contexto de pesquisa. As relações presentes na escola baseadas ora no ranqueamento dos alunos e num empreendendorismo de si (Gadelha, 2009), ora em processos cooperativos presentes em seu cotidiano, por vezes atravessavam a oficina de vídeo. Na EEEP, por exemplo, os próprios alunos se posicionaram de forma competitiva entre os vídeos de cada equipe, pois evitavam conversar entre si sobre seus projetos ou não queriam que as outras equipes vissem seus vídeos. Em contrapartida, na EEFM, produziu-se uma outra configuração: uma equipe ajudou a outra na criação dos vídeos. Quando os pesquisadores propuseram unir os vídeos, pois as cinco pequenas histórias versavam sobre o celular, os jovens de imediato ratificaram a ideia dizendo que não se tratava de uma competição. Esses dois fenômenos distintos nos forneceram bases de análise sobre os diferentes processos que têm levado esses jovens em direção ao mercado de trabalho.

Apesar dos fenômenos laborais de competição e concorrência atingirem os territórios de formas diferentes e de refletirem na necessidade da entrada no mercado de trabalho, mais presente no perfil da escola profissionalizantes (EEEP), a preocupação com o mundo do trabalho mostrou-se comum aos estudantes de ambas as escolas.

A insegurança dos alunos em final de curso frente ao início da atividade profissional faz com que pensem a necessidade da inserção no mercado de trabalho e sintam-se especialmente interessados em ferramentas instrumentalizadoras, como estratégias de busca de emprego, oficinas de currículo etc. (Bardagi, Lassance, Paradiso, \& Menezes, 2006). Ainda nas primeiras visitas às salas a fim de divulgação da oficina de vídeo, alguns alunos na EEEP, já inseridos nessa lógica, nos perguntaram se haveria entrega de certificados. Era clara a preocupação deles em adicionar experiências ao currículo, em busca de competitividade e empregabilidade. Na ocasião, esclarecemos que, apesar de o objetivo do trabalho não ser a profissionalização para o trabalho audiovisual, poderíamos fornecer uma declaração de participação.

$\mathrm{Na}$ EEFM a mesma preocupação com a inserção laboral foi observada quando alguns alunos pediram para que os encontros da oficina fossem aos sábados, pois estavam estagiando ou procurando emprego. No início da oficina, ao perguntarmos acerca de suas motivações e embora tivéssemos falado por diversas vezes que não havia objetivo de profissionalização, muitos a enxergavam como possibilidade de futura inserção laboral, para "trabalhar com vídeos e ter uma profissão garantida" (lago).

A questão da preparação da escola para o novo mundo do trabalho, marcado pelo empresariamento da sociedade (Gadelha, 2009), fica mais evidente na EEEP, que tem como objetivo a formação profissional ainda no Ensino Médio, onde no $3^{\circ}$ ano, tem no seu currículo a realização dos estágios. $O$ discurso de que "o bom comportamento dentro da escola hoje 
irá refletir no perfil profissional de amanhã" era incentivado e repetido cotidianamente pela coordenação da EEEP:

Joana (coordenadora): "A visão empresarial quer produtividade, e, a partir do instante em que existe assim... a pessoa sai um pouco para o lazer no ambiente de trabalho... e a mesma coisa do trabalho para casa, pra fazer em casa... mas o empresário não tem essa visão. Então, existe sim essa cobrança de ser focado no trabalho. Tem que ser focado no trabalho".

Tatiana: "Mas, hoje em dia, eu acho que os empresários tão tanto como a gente, porque tem empresários muito jovens que utilizam muito o Facebook. Eu vi muitas empresas no Facebook usando como uma forma de distribuir a sua marca".

Joana (coordenadora): "Não... com certeza nesse sentido, mas a questão de estar exclusivamente no lazer, isso atrapalha. É isso que tá sendo cobrado da gente, pra gente trabalhar essa postura".

Aliado aos discursos de competição e empregabilidade, a falta de tempo, também comum ao mundo laboral, atravessou o campo da pesquisa. Na EEEP era uma reclamação constante dos alunos, pois, segundo eles, estavam sempre cheios de aulas, de trabalhos e de provas. Isso, inclusive, marcou nossa negociação em combinar dias de nos encontrarmos para as oficinas. Tal situação pode ser evidenciada pelo relato de um dos estudantes, o qual salienta a falta de tempo até mesmo para acessar redes sociais:

Danilo: Não sei o pessoal do segundo ano, mas provavelmente quando eles tiverem no terceiro ano, estagiando, eles vão ver que não vai ter mais saco, vão ficar assim ó "como eu passava tanto tempo da minha vida no Facebook, quando eu poderia tá fazendo atividade", que agora a gente não tem mais tempo nem de fazer atividade. O professor passa e a gente tem que fazer na aula dele porque não tem tempo. A gente chega em casa vai jantar, dormir e já amanhece o dia e a gente tem que vir pra cá de novo.

$\mathrm{Na}$ EEFM, as falas surgiram numa outra direção, já que eles falavam de certo tempo ocioso fora da escola. Inclusive chegaram a reclamar do fato de que a oficina iria acabar, pois não sabiam o que fariam com esse tempo livre nas manhãs de sábado. Isso evidencia outra questão comum à população da periferia, a falta de espaços de lazer e cultura (Abramo \& Branco, 2008).

\section{Discussão}

\section{A singularidade das escolas e a pesquisa}

Os analisadores relações intraescolares e atravessamentos do mundo laboral no cotidiano escolar foram discu- tidos tendo como base o entrelaçamento pesquisa-escola. Como a pesquisa entra na escola e como a escola entra na pesquisa? Em outras palavras, como a nossa presença marca uma mudança, uma diferença no cotidiano da escola e como o nosso encontro com a escola transforma a hipótese de trabalho, a teoria e nós pesquisadores?

Desde o início tínhamos claro não ter sido demandada a pesquisa pelas escolas envolvidas e que foi a nossa equipe que as procurou, dado que não poderia ser desprezado. No entanto, no desenvolvimento do processo em cada escola, novas configurações ocorreram. Se no início por vezes a demanda nos era solicitada, sobretudo pelo grupo gestor, para atendimento aos alunos com dificuldades, aos poucos processos colaborativos e dialógicos foram se constituindo e novas demandas para a Psicologia Educacional foram problematizadas no espaço escolar. Conversas sobre o uso do celular, os limites e possibilidades das novas tecnologias para fins didáticos, as habilidades das novas gerações com a mídia, entre outros temas, eram trazidas por jovens, gestores e professores como campo de interesse para a escola.

A configuração da pesquisa, sobretudo através da oficina de vídeo, teve dois desdobramentos que também dizem respeito da singularidade dos processos escolares. $\mathrm{Na}$ EEEP, no final da pesquisa a diretora nos procurou para perguntar se poderíamos contribuir para pensar um projeto para a inserção de um curso profissionalizante em audiovisual na escola. Eles em breve se mudariam para um novo prédio, adaptado à realidade de escola profissionalizante, e seria então o momento de repensar as novas demandas locais. Segundo a diretora, ela havia sentido o grande interesse e mobilização dos alunos na criação dos vídeos e por isso havia tido esta ideia. Na ocasião nos colocamos disponíveis para colaborar na elaboração de um possível projeto. No entanto, não fomos mais procurados.

$\mathrm{Na}$ EEFM, na discussão sobre o possível público para a exibição final dos vídeos, os alunos foram unânimes ao afirmar que gostariam de mostrar a produção para os professores e núcleo gestor. Além de ser este um momento de visibilidade e valorização de algo produzido por eles mesmos, também poderiam reivindicar a criação de um grupo de audiovisual com apoio da escola, a exemplo da rádio escola já existente e que muitos faziam parte.

Eles sentiam que a nossa presença poderia respaldá-los. E assim foi na exibição. No debate seguido dos vídeos solicitaram a criação do grupo, o que foi bem acolhida pelos presentes. No entanto, não temos dados dos desdobramentos.

Tanto a escola profissionalizante (EEEP) quanto a regular (EEFM) pareceram incorporar a pesquisa baseadas em práticas discursivas e não discursivas já conhecidas. A EEEP traduzindo em possibilidade laboral e a EEFM com base na reinvindicação estudantil. Dois desdobramentos, duas singularidades que falam do cotidiano institucional de cada escola. Em ambos um campo comum, a pesquisa-intervenção como abertura de um novo possível, como catalizadora de mudança, de ressignificação do território escolar.

Por outro lado, a possibilidade de pesquisar COM os jovens, COM as escolas trouxe para o campo da pesquisa 
questionamentos do processo de pesquisar. Por vezes nos vimos na oficina de vídeo reproduzindo uma posição pouco dialógica, afeita a apenas transmitir informação, encerrando o outro na condição de não saber, que nós mesmos tanto criticávamos, ou seja, éramos objetivados por aquilo que pretendíamos objetivar (Lourau citado por Paulon, 2005). Assim, no processo de pesquisar COM faz-se sempre necessária a invenção de novas práticas, isto é, a própria (re) invenção da pesquisa.

\section{Referências}

Abramo, H. W. \& Branco, P. P. M. (Orgs.). (2008). Retratos da juventude brasileira: análises de uma pesquisa nacional. São Paulo: Perseu Abramo.

Aguiar, K. F., \& Rocha, M. L. (2007). Micropolítica e o exercício da pesquisa-intervenção. Psicologia, Ciência e Profissão, 27 (4), 648663.

Bardagi, M., Lassance, M. C. P., Paradiso, A. C., \& Menezes, I. A. (2006). Escolha profissional e inserção no mercado de trabalho: percepções de estudantes formandos. Psicologia Escolar e Educacional, 10(1), 69-82. Recuperado: 22 nov 2014. Disponível: http://www.scielo.br/scielo.php?script=sci_arttext\&pi $\mathrm{d}=$ S141385572006000100007\&ln g=pt\&tlng=pt. 10.1590/S141385572006000100007.

Boarini, M. L. (2013). Indisciplina Escolar: uma construção coletiva. Psicologia Escolar e Educacional, 17(1)

Carvalho, S. R. de \& Martins, L. M. (2013). A escola pública e as competências para o mercado: realidade e mitos. Psicologia Escolar e Educacional, 17(1), 141-149. Recuperado: 20 nov 2014. Disponível: http://www.scielo.br/scielo.php?script=sci_ arttext\&pid=S1413-85572013000100015\&Ing=pt\&tlng=pt. 10.1590/S1413-85572013000100015.

Castro, L. R. (2008). Conhecer, transformar (-se) e aprender: pesquisando com crianças e jovens. Em L. R. Castro \& V. Besset (Orgs.), Pesquisa-intervenção na infância e juventude, Rio de Janeiro, NAU/FAPERJ, p. 21-42.

Castro, L. R. (2011). Os jovens podem falar? Sobre as possibilidades políticas de ser jovem hoje. Em J. Dayrell, M. I. C. Moreira e M. Stengel (Orgs.), Juventudes Contemporâneas: um Mosaico de Possibilidades (pp. 299-324). Belo Horizonte: Ed. Puc-Minas.

Coelho, R. N. \& Aquino, C. A. B. (2009). Inserção laboral, juventude e precarização. Revista Psicologia Política, 9(18), 275-289.

Colaço, V. \& Cordeiro, A. (Org.) (2013). Adolescência e Juventude: Conhecer para Proteger. São Paulo: Casa do Psicólogo.

Foucault, M. (1979). Poder-Corpo in Microfísica do Poder (pp.145152). São Paulo: Graal.
Foucault, M. (2007). Vigiar e punir: nascimento da prisão (Ramalhete, R., Trad.). Petrópolis, RJ: Vozes.

Gadelha, S. (2009). Biopolítica, governamentalidade e educação. Belo Horizonte: Autêntica.

Lima, M. F. \& Jimenez, S. V. (2011). O complexo da educação em Lukács: uma análise à luz das categorias trabalho e reprodução social. Educação em revista, 27 (2), 73-94. Recuperado: 21 mar 2013. Disponível: http://www.scielo.br/pdf/edur/v27n2/a05v27n2. pdf.

Lourau, L. (1993). René Lourau na UERJ. Análise Institucional e Práticas de Pesquisa. Rio de Janeiro: ed. UERJ.

Miranda, L. L., Khouri M. M., Rodrigues, D. C., Amaral, N. D. , \& Sousa, J. K. M. (2013). Consumo e produção midiática por estudantes de escolas públicas de Fortaleza/Brasil. Revista Interacções, 9, 169190.

Miranda, L. L. (2014a). Escola e Mídia: Encontros Possíveis, Despedidas Necessárias. Anais VII Colóquio Internacional de Filosofia da Educação. Recuperado: 10 nov 2014. Disponível: http://www.filoeduc.org/viicife/adm/impressos/trabalhos/TR420. pdf.

Miranda, L. L. (2014b). Uma câmera na mão e um dispositivo na cabeça: Carta Aos Pesquisadores. Em: G. Tavares, M. Moraes, \& A. Bernardes (Orgs.), Cartas para pensar: políticas de pesquisa em psicologia (pp. 77-88). Vitória: EDUFES.

Miranda, L. L., Souza Filho, J., Queiroz, L. L., Viana, V. M, \& Coelho, D.O. (no prelo). Modos de subjetivação e redes sociais digitais: dialogando com jovens estudantes de escolas públicas de Fortaleza-CE. Em C.A. M. Sousa (Org.), Juventudes e Tecnologias: Sociabilidades e Aprendizagens. Brasília: Liber Livros/ UNESCO.

Moraes, M. (2014). Do "Pesquisar COM" ou tecer e destecer fronteiras. Em G. Tavares, M. Moraes, \& A. Bernardes, A. (Orgs.), Cartas para pensar: políticas de pesquisa em psicologia (pp. 131138). Vitória: EDUFES.

Nardi, H.C. (2006) Ética, trabalho e subjetividade: trajetórias de vida no contexto do capitalismo contemporâneo. Porto Alegre: UFRGS.

Paulon, S. M. (2005). A Análise de Implicação como Ferramenta na Pesquisa-intervenção. Psicologia \& Sociedade, 17 (3), 18-25. Recuperado: 7 abr. 2013. Disponível: http://www.scielo.br/pdf/ psoc/v17n3/a03v17n3.pdf.

Rocha, M. L. (1996). Do Tédio à Cronogênese: uma Abordagem Ético-estético-política da Prática Escolar. Tese de doutorado, Pontifícia Universidade Católica de São Paulo, São Paulo.

Rocha, M. L. (2001). Formação e Prática Docente: Implicações com a Pesquisa-Intervenção. Em I. M. Maciel (Org.), Psicologia e Educação: Novos Caminhos Para a Formação (pp. 175-191). Rio 
de Janeiro: Ciência Moderna.

Rocha, M. L. \& Aguiar, K. F. de. (2010). Entreatos: percursos e construções da psicologia na rede pública de ensino. Estudos e Pesquisas em Psicologia, 10(1) Recuperado: 10 jan. de 2015. Disponível: http://pepsic.bvsalud.org/scielo.php?script=sci_arttext \&pid=S180842812010000100006 \&lng=pt\&tIng=pt.
Santos, N. I. S. \& Barone, L. R. (2006). Uma pesquisa intervenção em análise: militância, sobreimplicação ou ato político? Em A. M. Machado, M. L. Rocha, \& A. M. Fernandes (Orgs.), Novos possíveis no encontro da psicologia com a educação. São Paulo: Casa do Psicólogo, p. -67.

Sibilia, P. (2012). Redes ou paredes: a escola em tempos de dispersão (Ribeiro, V., Trad.). Rio de Janeiro: Contraponto.

Recebido em: 24/02/2015

Reformulado em: 21/08/2015

Aprovado em: 09/11/2015

\section{Sobre as autoras}

Luciana Lobo Miranda (lobo.lu@uol.com.br)

Doutora em Psicologia pela PUC-RJ. Professora do Programa de Pós-Graduação em Psicologia da Universidade Federal do Ceará (UFC). Pesquisadora CNPq.

Eveline Nogueira Pinheiro de Oliveira (nogueiraeveline@hotmail.com)

Mestranda no Programa de Pós-Graduação em Psicologia da Universidade Federal do Ceará (UFC). Bolsista CAPES. Graduada em Psicologia pela Universidade Federal do Ceará (UFC).

Júlia Evangelista Mota Shioga (juliashioga@hotmail.com)

Graduada em Psicologia pela Universidade Federal do Ceará (UFC). Pós-graduanda pelo Programa de Residência Integrada da Escola de Saúde Pública do Ceará (ESP-CE).

Denise Costa Rodrigues (denisecrodriguess@gmail.com)

Mestranda em Psicologia pela Universidade Federal do Ceará (UFC). Bolsista Capes.

Agradecimento ao CNPq pelo Financiamento da Pesquisa. Pesquisa Aprovada no Comitê de Ética (CONEP). 